\title{
Article \\ Deducing of Optical and Electronic Domains Based Distortions in Radio over Fiber Network
}

\author{
Haoyu Yu ${ }^{1}$, Farman Ali ${ }^{2}$, , Shanshan Tu ${ }^{3, * D}$, Hanen Karamti ${ }^{4}$, Ammar Armghan ${ }^{5}$ (D), Fazal Muhammad ${ }^{6}$ (D), \\ Fayadh Alenezi ${ }^{5}$ (D), Khurram Hameed ${ }^{7}$ and Nauman Ahmad ${ }^{8}$ (D)
}

1 Faculty of Information Technology, Beijing University of Technology, Beijing 100124, China; yhy990820@163.com

2 Department of Electrical Engineering, Qurtuba University of Science and IT, Dera Ismail Khan 29050, Pakistan

3 Engineering Research Center of Intelligent Perception and Autonomous Control, Faculty of Information Technology, Beijing University of Technology, Beijing 100124, China

4 Department of Computer Sciences, College of Computer and Information Sciences, Princess Nourah Bint Abdulrahman University, P.O. Box 84428, Riyadh 11671, Saudi Arabia; Hmkaramti@pnu.edu.sa

5 Department of Electrical Engineering, College of Engineering, Jouf University, Sakaka 72388, Saudi Arabia; aarmghan@ju.edu.sa (A.A.); fshenezi@ju.edu.sa (F.A.)

6 Department of Electrical Engineering, University of Engineering Technology, Mardan 23200, Pakistan; fazal.muhammad@uetmardan.edu.pk

7 Department of Electrical Engineering, International Islamic University, Islamabad 44000, Pakistan; khurram.phdee112@iiu.edu.pk

8 School of Marine Science and Technology, Northwestern Polytechnical University, Xi'an 710600, China; nauman@mail.nwpu.edu.cn

* Correspondence: drfarmanali.optics@qurtuba.edu.pk (F.A.); sstu@bjut.edu.cn (S.T.)

check for

updates

Citation: Yu, H.; Ali, F.; Tu, S.;

Karamti, H.; Armghan, A.;

Muhammad, F.; Alenezi, F.; Hameed,

K.; Ahmad, N. Deducing of Optical

and Electronic Domains Based

Distortions in Radio over Fiber

Network. Appl. Sci. 2022, 12, 753.

https://doi.org/10.3390/

app12020753

Academic Editor: Ernesto Limiti

Received: 14 December 2021

Accepted: 10 January 2022

Published: 12 January 2022

Publisher's Note: MDPI stays neutral with regard to jurisdictional claims in published maps and institutional affiliations.

Copyright: () 2022 by the authors Licensee MDPI, Basel, Switzerland. This article is an open access article distributed under the terms and conditions of the Creative Commons Attribution (CC BY) license (https:// creativecommons.org/licenses/by/ $4.0 /)$.

\begin{abstract}
Managing the users multimedia and long-range based demands, the radio over fiber (RoF) mechanism has been introduced recently. RoF mingles the optical and radio communication frameworks to increase mobility and offer high capacity communication networks (CNs). In this paper, a full-duplex RoF-based $\mathrm{CN}$ is investigated for the next-generation passive optical network (PON), utilizing wavelength division multiplexing (WDM) technology. The desolations on account of optical and electronic domains (OEDs) are addressed, using dispersion compensation fiber (DCF) and optical and electrical filters, including modulation scheme. The analytical and simulation models are analyzed in terms of phase error (PE), radio frequency (RF), fiber length and input and received powers. The performance of the proposed model is successfully evaluated for $50 \mathrm{~km}$ range, -40 to $-18 \mathrm{dBm}$ received power, -20 to $0 \mathrm{dBm}$ input power, where below $10^{-6}$ bit error rate (BER) is recorded. Thus, this signifies that the presented model exhibits smooth execution against OEDs impairments.
\end{abstract}

Keywords: full duplex RoF technology; issues related to optical and electronic domains; next generation passive optical networks; dispersion compensation fiber; modulation format

\section{Introduction}

The traffic on internet services has been increased exponentially in the last few years, and it is expected that the data rate demands will touch the zettabyte digit between 2022 to 2025 [1,2]. Therefore, a developed approach is required to support growing needs like propagation range and multimedia based data transmissions. Passive optical networks (PONs) are considered fruitful solutions for transmitting high capacity data with minimum bit error rate (BER). Furthermore, the installation of PONs is acceptable to the entire world for increasing speed and capacity to the users $[3,4]$. However, the wired based PONs contain extra issues like nonlinear impairments (NLIs) while transmitting high bandwidth data over fiber for long range, which badly disturbs the system flexibility [5]. On the other side, the physical-less based communication network $(\mathrm{CN})$ presents accurate probability 
within the flexible environment; however, it fails to accommodate a considerable number of users with the high bandwidth capacity of long range transmission [6]. Thus, to overcome on NLIs and support above mentioned demands, the new approach named radio over fiber (RoF) links is developed, which combines the physical and physical-less setups of CNs [7-10]. Moreover, the wavelength division multiplexing (WDM) technology and advanced modulation schemes have developed the fidelity many times of the RoF system. This advanced methodology of CN minimizes the NLIs, and the system performance increase in terms of transmission range, number of users and capacity. In contrast, the RoF system uses the concept of electrical to optical $(\mathrm{E} / \mathrm{O})$ and visual to electrical $(\mathrm{O} / \mathrm{E})$ conversion procedures, which make space for the peak to average power ratio impairments (PAPRIs) [11,12]. Therefore, this paper investigates the novel WDM based RoF technology which aims to suppress the NLIs and PAPRIs.

\subsection{Related Work}

The RoF technology is considered a unique solution to design the CN healthier against NLIs and PAPRIs. Various researchers have already worked on NLIs and PAPRIs and made some productive solutions. Some of them are discussed as follows. In [13], authors have studied a novel adaptive RoF system for next-generation cloud radio access network, which goal is to maintain power consumption and to compensate NLIs. In [14], the authors have developed $2 \times 2$ multiple input multiple output based OFDM methodology for improving the RoF structure functionalities. An advanced WDM-RoF system is discussed in $[15,16]$, where $0.45 \mathrm{~nm}$ are chosen for channel transmission with keeping constant the input power. The study in [17] explores multi-mode operation in RoF technology using multi-wavelength optical comb and pulse shaping. The 4QAM-OFDM procedure is applied before transmitting signals over WDM within a 5G carrier frequency. In [18], the authors have employed a cascaded in-pulse quadrature modulator and intensity modulator for D-band vector millimetre waves in the RoF system. Muramoto et al. in [19] have presented a graded-index plastic optical fiber technique for OFDM based RoF system to minimize noise and distortions. In [20], authors have demonstrated that an RF transmission system in S-band using $2 \times 2$ multi input multi output (MIMO)-OFDM with orthogonal and biorthogonal wavelets, employing phase shift keying (PSK) modulation format. In [21], Coelho et al. have proposed the OFDM based WDM RoF system by applying fiber brag grating (FBG).

However, these previously proposed solutions are limited to addressing NLIs and PAPRIs for long range transmission CNs. Moreover, these schemes require different costly carriers to transmit long distances with low BER data. In the existing models, the phase errors (PEs), NLIs and PAPRIs are not studied for RoF system, which have limited the high capacity fifth generation services. The enhancement in online services and long range range communication requirements, it is necessary to minimize the issues generated by PEs, NLIs and PAPRIs. Therefore, in this paper, based on PON, a full duplex RoF system is presented, using WDM technology to decrease the factors of NLIs and PAPRIs.

\subsection{Major Contributions}

This section shows that multimedia and transmission range demands are significant issues in today's world. Secondly, High bandwidth capacity and long distance CNs include the issues like NLIs. The full duplex WDM-RoF CN also produces PAPRIs by reason of $\mathrm{O} / \mathrm{E}$ and $\mathrm{E} / \mathrm{O}$ conversions. The main objectives of this system are to manage the NLIs and PAPRIs, that ROF could transmit data up to a long range, including maximum capacity information. The primary goals of the proposed framework are listed as follows.

1. The techniques like balancing phase error (PE), dispersion compensation fiber (DCF), optical and electrical filters and full duplex RoF CN are applied for investigating and compensating the NLIs and PAPRIs.

2. The mathematical estimations are conducted for the above mentioned techniques aiming to enhance the accuracy of the proposed RoF system. 
3. The simulation model is examined using the analytical approach in terms of laser power, received power, RF frequency, fibre length, and filters.

4. Two measuring parameters, bit error rate (BER) and normalized signal to noise ratio, are used to estimate the conduction of the proposed RoF model against PAPRIs, NLIs and PEs.

Following the introduction section, the rest of the paper includes the layout of the proposed model in Section 2, analytical modelling in Section 3, results and discussion of offered CN in Section 4 and conclusion of the proposed system in Section 5.

\section{Proposed Radio over Fiber Network}

The detailed structure of the proposed full-duplex RoF model, aiming to suppress the factors of NLIs and PAPRIs, is presented in Figure 1. WDM multiplexing and demultiplexing techniques are applied, linking $N$ channels within the central station (CS) and base station (BS) for upstream and downstream signals. At input side, the CS block covers continuous wave (CW) laser with $193.1 \mathrm{THz}$ launching frequency and $5 \mathrm{MHz}$ linewidth, launch power under -20 to $0 \mathrm{dBm}$ range, pseudo-random bit sequence (PRBS) generator to induce $100 \mathrm{Gbps}$ for initiating Gaussian pulse generator, and radio frequency (RF) based amplitude modulator, converting baseband signals into RF clock utilizing amplitude shift keying (ASK) [22]. Similarly, essential parameters like hybrid coupler (HC) operating at $90^{\circ}$ is also installed inside CS. Which function is to attain the integrated RF and subcarrier multiplexed signals. Moreover, the process of getting information in the optical domain is performed in the CS section with the help of a dual drive and dual-port liNb much Zehnder modulator (MZM). It takes two forms of signals from $90^{\circ} \mathrm{HC}$ and optical waves from CW laser. The CS outflow is connected to WDM multiplexer reflective wavelength block-1 for transmitting and receiving the upstream and downstream signals. WDM multiplexer transmitter optical signals over single-mode fiber (SMF), purposing to cover long-range. In order to minimize the impact of NLIs and PAPRIs and balance the phase of propagating signals, SMF is followed by DCF and erbium-doped fiber amplifier (EDFA). Correspondingly, the BS block comprises WDM de-multiplexer, PIN photodetector, bandpass filter (BPL), RF de-modulator, BER analyzer and reflected wavelength block- 2 . The block of reflected wavelength reuses the downstream wavelength without the extra component of the CW laser. The performance of the received upstream signal through SMF is evaluated by a BER analyzer. The list of used parameters for investigating outcomes of the proposed full-duplex RoF model is depicted in Table 1.

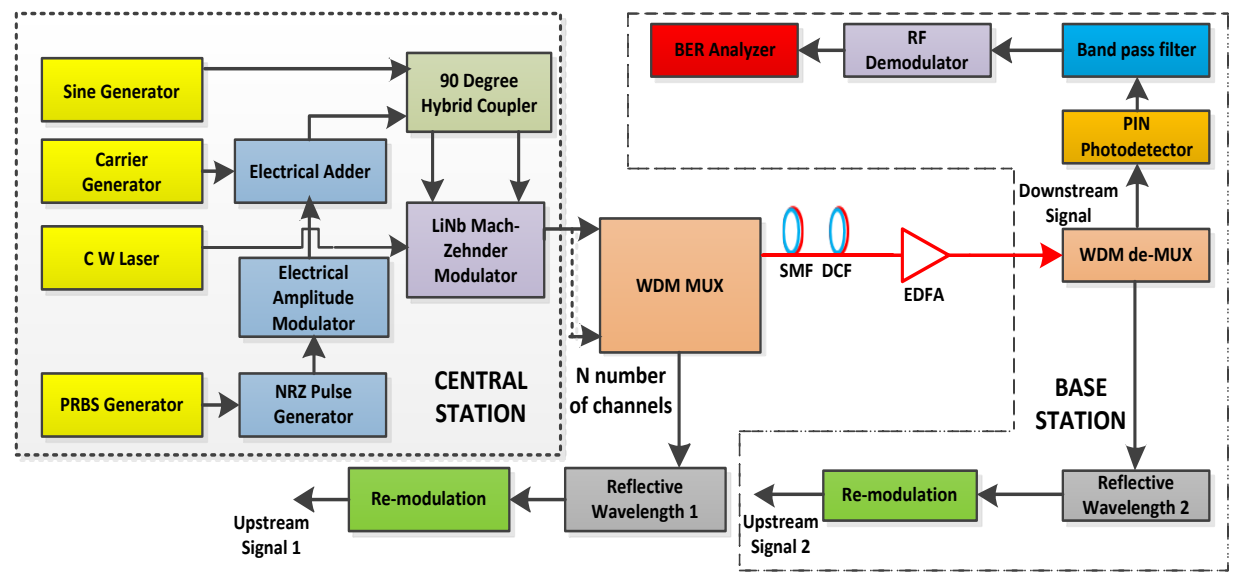

Figure 1. WDM based full duplex RoF system including CS and BS. 
Table 1. List of elements applied for measuring the proposed model outcomes.

\begin{tabular}{lc}
\hline Description & Magnitude \\
\hline Effective area & $80 \mathrm{~mm}^{2}$ \\
Launch power & -19 to $1 \mathrm{dBm}$ \\
Transmission range & 1 to $10 \mathrm{~km}$ \\
Received power & $-40 \mathrm{dBm}$ to $-20 \mathrm{dBm}$ \\
Spacing among channels & 25 to $50 \mathrm{GHz}$ \\
Reference wavelength & $1553 \mathrm{~nm}$ \\
Channel Quantity & $4-16$ \\
Nonlinear dispersion & $-2.5 \mathrm{ps}^{3} / \mathrm{km}$ \\
RF range & 4 to $6 \mathrm{GHz}$ \\
Line width & $5 \mathrm{MHz}$ \\
Extension ratio & $10 \mathrm{~dB}$ \\
\hline
\end{tabular}

\section{Mathematical Calculations for Optical and Electronic Domains Based Parameters in Radio over Fiber Network}

The fiber cable provides medium to deliver the wireless signals in their own RF waves as declared in Figure 2. It can be seen that the RoF system directly convert the optical signals into RF at high frequency. The optical signal of RF waves at the transmitter can be estimated [23-25] as

$$
\mathrm{E}(t)=\mathbb{A}+\cos \left[\mathrm{w}_{\mathrm{O}}+3 \mathrm{w}_{\mathrm{LO}}\left(t+\mathrm{d}_{\tau}\right)+\theta\right]
$$

where $\mathbb{A}$ is the amplitude of the signal, wo denotes angular frequency of the optical signal, $\mathrm{w}_{\mathrm{LO}}$ describes the angular frequency of local oscillator $(\mathrm{LO}), \mathrm{d}_{\tau}$ is the time delay and $\theta$ is the phase of the optical signal.

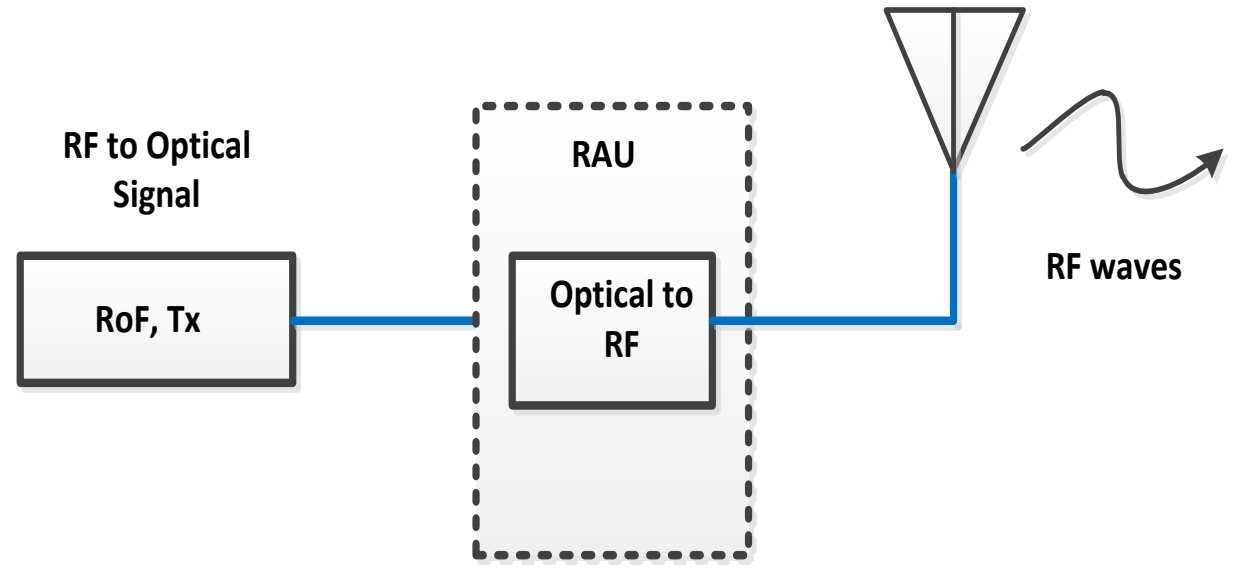

Figure 2. RF and optical waves convergence scheme.

The induced multilevel pulses are estimated as [26-28] as

$$
N_{\text {out }}(t)=\left\{\begin{array}{l}
a, 0 \leq t<t_{1} \\
b N_{\text {in }}(t)+a, t_{1} \leq t<t_{1}+t_{c} \\
a, t_{1}+t_{c} \leq t<T
\end{array}\right.
$$

where the incoming signals are denoted by $N_{i n}$, linear gain is presented by $b, a$ is applied for bias parameters, bit period is defined by $T, t_{c}$ is the duty cycle and pulse position 
is denoted by $t_{1}$. The waves explain in Equation (4) are interfered by $\mathrm{HC}$ with $50 \mathrm{MHz}$ frequency [29], which output is given as

$$
\begin{aligned}
N_{\text {out }}(t)= & D\left[I(t) \cos \left(2 \pi f_{c} t+\omega_{c}\right)-\right. \\
& \left.Q(t) \sin \left(2 \pi f_{c} t+\omega_{c}\right)\right]+a
\end{aligned}
$$

Here electrical input signals are shown by $I$ and $Q, D$ means gain of element, $f_{c}$ is the carrier frequency and $\omega_{c}$ is phase of the signal. To estimate the PAPRTs, considering liNb MZM transmission with $n$ sub-carriers with frequencies $\left(f_{i}, i=1,2, \ldots, n\right)$. The continuous time signal $S(t)$ based on modulation interval $T$ and $n T$ duration of inter symbol interference (ISI) [30-32] is defined as

$$
S(t)=\frac{0 \leq t<n T^{\max }|\zeta(t)|^{2}}{E|\zeta(t)|^{2}}
$$

The parameter $E[\zeta(t)]$ explains the expectation. The gain of electrical amplifier which suppress the high PAPRIs [33-36] is measured as

$$
\frac{P_{\text {out }}}{P_{\text {in }}}=10^{b / 10}
$$

The outcomes of Equation (7) are measured in $d B$, which gives the amplifies electrical signals and is presented as

$$
E_{\text {out }}=E_{\text {in }} \sqrt{ } b
$$

At the presence of PAPRIs and NLIs the power spectral density (PSD) function is induced and calculated as

$$
P S D=\sqrt{ } P_{\text {noise }} \cdot f_{S}
$$

Here $P_{\text {noise }}$ means the noise power and $f_{s}$ denotes the frequency grid spacing which is defined as

$$
f_{s}=\frac{R_{s}}{\psi_{s}}
$$

In order to transmit the RF signals over optical $\mathrm{CN}$ the laser source is needed. So, in this model CW optical laser source is used. The electric field intensity of CW laser is define as

$$
E_{1}=E_{0} e^{j 2 \pi f_{c} t}
$$

From Equation (1) to Equation (10) the cosine of RF signal $S(t)$ is calculated as

$$
S(t)=V_{R F} \cos (2 \pi f)
$$

where $V_{R F}$ shows the driving voltage of RF. The optical field at output of intensity modulatot (IM) is given as

$$
E_{1}=\frac{E_{0}}{2}\left[e^{j \pi\left(\frac{V_{D C}+S(t)}{V_{\pi}}\right)}+e^{-j \pi\left(\frac{V_{D C}+S(t)}{V_{\pi}}\right)}\right]
$$


where $V_{D C}$ is the DC bias voltage and $V_{\pi}$ explains the IM half wave voltage. Assuming $\xi=\pi V_{R F} / V_{\pi}$ and $\omega=\pi V_{D C} / V_{\pi}$, which explain the modulation index and initial phase caused by $V_{D C}$ of the IM respectively. From Equation (13) the $E_{1}$ can be extended as

$$
\begin{array}{r}
E_{1}(t)=E_{0} \exp \left(j 2 \pi f_{c} t\right) . \\
\left\{\begin{array}{l}
\cos \omega\left[J_{0}(\xi)+2 \Sigma_{i=1}^{\infty}(-1)^{i} J_{2 i}(\xi) \cos \left(4 i \pi f_{s} t\right)\right] \\
+\sin \omega\left[2 \Sigma_{i=1}^{\infty}(-1)^{i} J_{2 i-1}(\xi) \cos (2 i-1) 2 \pi f_{s} t\right]
\end{array}\right.
\end{array}
$$

Here $J_{i}$ means the $i$ th order of Bessel function. The transfer function of the transmitted signal is measured as

$$
H(f)= \begin{cases}\alpha & \left(|f|<f_{1}\right) \\ \beta & \left(f_{1} \leq|f|<f_{2}\right) \\ 0 & f_{2}<|f|\end{cases}
$$

where $\beta$ is written as

$$
\beta=\sqrt{ } 0.5 \alpha^{2} .1+\cos \left(\left(|f|-f_{1} / r_{p} . \delta\right) . \pi\right)
$$

Here $\alpha$ denotes insertion loss, $r_{p}$ means roll of factor and $f_{1}, f_{2}$ are calculated as

$$
\begin{aligned}
& f_{1}=1-r_{P} f_{c}\left(0 \leq r_{p} \leq 1\right) \\
& f_{2}=1+r_{P} f_{c}\left(0 \leq r_{p} \leq 1\right)
\end{aligned}
$$
below:

To describe, measuring the NLIs in the propagation of light wave in fiber are given

$$
\begin{aligned}
& \left.i \partial A / \partial z-\beta_{2}\left(\partial^{2} A\right) /\left(\partial t^{2}\right)-i \beta_{3} \partial^{3} A\right) /\left(\partial t^{3}\right)+\gamma|A|^{2} A \\
& =-i \alpha / 2 A
\end{aligned}
$$

where complex term of electromagnetic field is defined by $A, z$ is the fiber distance, $t$ is the time, $\beta_{2}$ and $\beta_{3}$ are the group velocity dispersion (GVD) and nonlinear dispersion, respectively. The term $\gamma$ is used for nonlinear coefficient and $\alpha$ means attenuation of the fiber. The nonlinear coefficient is further calculated as in terms of nonlinear refractive index $n_{2}$ and carrier wavelength $\lambda_{0}$.

$$
\gamma=\left(2 \pi n_{2}\right) / \lambda_{0}
$$

The estimation of power consumption is written as,

$$
\begin{array}{r}
P_{T}=\Omega_{D}^{-1} C\left(P_{C W}+P_{\text {map }}+\right. \\
\left.P_{H C}+P_{I S I}+P_{\text {reflectiveblock-1 }}+n_{M Z M} \cdot P_{M Z M}\right)
\end{array}
$$

where $\Omega$ denotes power conversion efficiency, $P_{\text {map }}$ is the signal mapping of power consumption, $P_{H C}$ means power consumption due to HC, $P_{I S I}$ explains ISI power consumption, $P_{\text {reflectiveblock-1 }}$ denotes power consumption reflective block- 1 and $n_{M} Z M$ means the quantity of MZMs required for WDM-RoF transmission. Similarly, the power consumption at the $\mathrm{Rx}$ side is measured as

$$
\begin{array}{r}
P_{R}=\Omega_{D}^{-1} C\left(P_{\text {WDMde-MUX }}+P_{P D}+P_{\text {re-modulation }}+\right. \\
\left.P_{I S I}+P_{\text {amp }}+P_{\text {reflectiveblock-2 }}\right)
\end{array}
$$

The parameters $P_{W D M d e-M U X}, P_{P D}, P_{r e-\text { modulationi }}, P_{I S I}, P_{\text {reflectiveblock-2 }}$ and $P_{\text {amp }}$ define the power consumption because of WDM de-MUX, PD, re-modulation, ISI transmission, amplification and reflective block-2, respectively. The BER is used for the analysis of 
NLIs and PAPRIs parameters, means that if these issues exist then how many bit can be transferred including low error size per bit. BER is given as

$$
\mathrm{BER}=\frac{1}{2 \operatorname{erf} \sqrt{\frac{\mathrm{OSNR}}{2}}}
$$

The $\operatorname{erf}$ denotes error function the optical signal to noise ratio (OSNR) is described as

$$
\text { OSNR }=E_{S N R} \frac{\varphi}{2 B_{r} \cdot m_{\text {sys }}}
$$

where $B_{r}$ defines the reference bandwidth, $E_{S N R}$ is the electrical SNR, $\varphi$ is the total transmission symbol rate measured in Gbps and the last term of Equation (22) $m_{\text {sys }}$ describes is the system margin.

\section{Experimental Analysis and Discussion}

This proposed model is analyzed analytically in Section 3, which describes that NLIs and PAPRIs create discontinuity in the transmission signals. Furthermore, current CNs face high capacity demands, the number of channels, data rates, and long transmission path. The full-duplex RoF-based CN is analyzed in this model to minimize the order of NLIs and PAPRIs. The simulation results are investigated in this section based on block description and analytical models.

The performance analysis of received power and BER, 1 to $10 \mathrm{~km}$ of transmission length, and 4 to $6 \mathrm{GHz} \mathrm{RF}$ range are presented in Figure 3. At $-35 \mathrm{dBm}$ received power, the outcomes are achieved above the threshold range. The order of NLIs and PAPRIs are enhanced with transmission range and the frequency of RF waves. Below $10^{-4}$ and $10^{-5}$ BERs are achieved at $-20 \mathrm{dBm}$ received Power $10 \mathrm{~km}$ length for $6 \mathrm{GHz}$ and $4 \mathrm{GHz}$ $\mathrm{RF}$ waves, respectively. Thus, there is a 0.1 BER difference between 6 and $4 \mathrm{GHz} \mathrm{RF}$ transmission. The phase errors (PEs) are induced in the transmission pulses by reason of NLIs and PAPRIs, which impact is declared in for different $0,2.5,5$, and 8 deg PEs in terms of normalized signal to noise ratio and BER, with increasing PEs, the WDM-RoF presents the worst results. The simulation results in Figure 4 are investigated for $\mathrm{RF} 4 \mathrm{GHz}$, and length $5 \mathrm{~km}$, the maximum 8 deg PE attains the threshold early than 0,2 , and 2.5 deg PEs. The analysis of the normalized signal to noise ratio as a function of BER at $5 \mathrm{~km}$ and $6 \mathrm{GHz}$ RF waves is shown in Figure 5. This describes that with increasing the frequency of RF waves, the outcomes become worse as compared to Figure 4 which presents the outcomes of the presented model at $5 \mathrm{~km}$ and $4 \mathrm{GHz}$ RF range. Similarly, Figures 6 and 7 contain the results of the presented model of $4 \mathrm{GHz}$ and $6 \mathrm{GHz}$ RF range at $10 \mathrm{~km}$ transmission length. It is depicted from the results that the PEs factors disturb system fidelity. It is recorded that till six normalized signals to noise ratio, the outcomes of the full-duplex system are above the threshold BER. With increasing the PE till $8 \mathrm{deg}$, then the proposed model presents bad outcomes as shown in Figures 6 and 7. Greater than seven normalized signals to noise ratio, the factors of NLIs, and PAPRIs are compensated successfully as declared in Figures 6 and 7. The main mechanisms to evaluate the PAPRIs and NLIs are full-duplex RoF linked with WDM and the DCF with $-20,-30,-35$, and $-40 \mathrm{ps} / \mathrm{nm} / \mathrm{km}$ dispersion magnitudes. These mentioned DCF dispersion are studied and analyzed using 4 and $6 \mathrm{GHz}$ RF waves and 5 to $10 \mathrm{~km}$ transmission range. Figure 8 explains the information among the transmission range and BER, for $-20,-30,-35$, and $-40 \mathrm{ps} / \mathrm{nm} / \mathrm{km}$ DCF dispersion values, operating at $4 \mathrm{GHz}$ RF range, which clarify that the above $8 \mathrm{~km}$ of fiber length the influences of NLIs and PAPRIs produce BER in the limited range. Moreover, the achievements of the full-duplex WDM based RoF model at $-40 \mathrm{ps} / \mathrm{nm} / \mathrm{km}$ DCF dispersion are efficient compared to -35 , -30 , and $20 \mathrm{ps} / \mathrm{nm} / \mathrm{km}$ dispersion of DCF. Keeping DCF dispersion at $-40 \mathrm{ps} / \mathrm{nm} / \mathrm{km}$ for $5 \mathrm{~km}$ fiber length and RF $4 \mathrm{GHz}, 2.2 \times 10^{-7} \mathrm{BER}$ is attained. On the other hand, the outcomes touch the threshold range by employing DCF with $-35,-30$, and -20 dispersion with the above-covered path and RF values. Figure 9 defines the same results as discussed 
in Figure 8 with transmission range and BER parameters, however here, the capacity of RF signals increased to $6 \mathrm{GHz}$. This concludes that the capacity of transmitted data has valuable contributions towards NLIs and PAPRIs. Figure 10 depicts the behavior of NLIs and PAPRIs and the proposed full-duplex RoF model and the outcomes while compensating these factors. The simulation results on account of launch power and BER are shown in Figure 10 RoF model, which covers $5 \mathrm{~km}$ transmission length and $4 \mathrm{GHz}$ RF capacity. The destructive analysis is presented when NLIs and PAPRIs are not balanced. The results in Figure 10 are compared among with addressed NLIs and PAPRIs and without addressed NLIs and PAPRIs. Moreover, the results include the individual performance of each addressed NLIs and PAPRIs and without addressed NLIs and PAPRIs, which denotes that in every case, the outcomes without addressing NLIs or PAPRIs are weak and interrupt CN efficiency. The order of NLIs and PAPRIs are increased directly with RF and transmitted length as presented in Figures 11-13. Figure 11 explores the relation among input power and BER for $5 \mathrm{~km} 6 \mathrm{GHz}$, Figure 12 presents the outcomes of the presented model based on input power and BER for $10 \mathrm{~km} 4 \mathrm{GHz}$ and Figure 13 defines the results at $10 \mathrm{~km}$ and $6 \mathrm{GHz}$ RF waves, using input power vs BER. In Figure 11 at $0 \mathrm{dBm}$ input power for $5 \mathrm{~km}$ length and $4 \mathrm{GHZ} \mathrm{RF,} 10^{-7}$ BER is attained, with applying management techniques, minimizing NLIs and PAPRIs. However, about 0.001 less BER is gained using a conventional system if no mechanism is installed for treating the effects of NLIs and PAPRIs. Similarly, $10^{-6}$ is calculated of the proposed full-duplex RoF model, working at $10 \mathrm{~km}$ and $4 \mathrm{GHz}$ RF parameters. Furthermore, Figure 13 estimates $10^{-5}$ and $3.1 \times 10^{-3}$ BER at $0 \mathrm{dBm}$, comparing compensation of NLIs and PAPRIs. From Figures 10-13 it is evaluated that outcomes of the full-duplex RoF model are destroyed badly if there are no procedures applied for deducing the NLI and PAPRIs. In addition, it is showed the negative impacts of NLIs are higher than PAPRIs. Figure 14 evaluates the received power vs input power at -10 to $0 \mathrm{dBm}$ for 1,5 , and $10 \mathrm{~km}$ fiber length and $6 \mathrm{GHz}$ RF waves. It is depicted from Figure 14 that for higher length because of NLIs, PAPRIs and PEs, the maximum penalty is recorded in received power. The presented model is also investigated, employing BER analyzer, optical spectrum analyzer and RF spectrum analyzer, which are explained in Figures 15a-d, 16a-d and 17a-d. Figure 15a shows the performance of the full-duplex RoF model at $10 \mathrm{~km}$ of transmission range and $6 \mathrm{GHz}$ of RF waves. When there is no technique addressed for controlling NLIs and PAPRIs. Figure $15 \mathrm{~b}$ presents the model without NLIs and PAPRIs compensated at $10 \mathrm{~km}$ and $4 \mathrm{GHz}$ RF waves. The compensated NLIs, PAPRIs results of the full-duplex RoF model where NLIs and PAPRIs are reduced depict in Figure 15c,d for $10 \mathrm{~km}, 4 \mathrm{GHz}$, and $10 \mathrm{~km} 6 \mathrm{GHz}$, respectively. Figure 16a shows the input transmitted signals, Figure 16b,c clarify without NLIs and PAPRIs managed signals at $5 \mathrm{~km}$ and $10 \mathrm{~km}$ of path cover with RF $4 \mathrm{GHz}$, respectively. The NLIs and PAPRIs compensated output signals at path cover of $10 \mathrm{~km}$ are presented in Figure 16d. Figure 17a contains the results of input signals. Figure $17 \mathrm{~b}$ consists of interrupted signals due to NLIs and PAPRIs of the proposed full-duplex RoF model at Length $=5 \mathrm{~km}$ and RF $=4 \mathrm{GHz}$. The worst performance at $10 \mathrm{~km}$ length and RF $4 \mathrm{GHz}$ of the model without compensated NLIs and PAPRIs is explained in Figure 17c. While outcomes of the applied technique to suppress NLIs, and PAPRIs at $10 \mathrm{~km}$ and RF $4 \mathrm{GHz}$ are described in Figure 17d. 


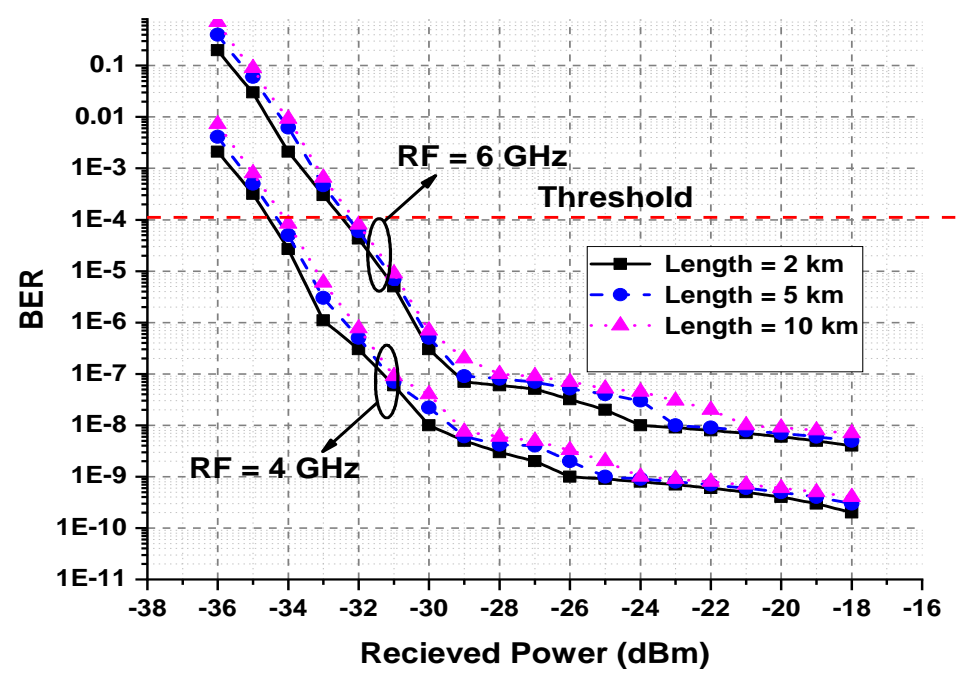

Figure 3. Received power against BER at 2, 5, $10 \mathrm{~km}$ fiber range, 4 and $6 \mathrm{GHz}$ radio frequency, and 100 Gbps data rate.

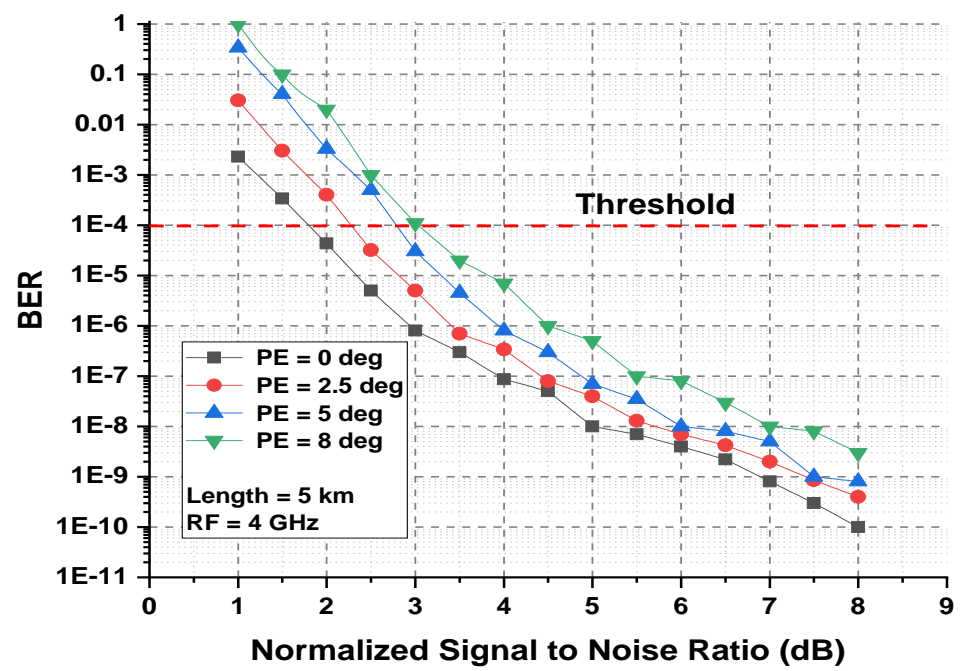

Figure 4. BER in terms of normalized signal to power ratio for fiber length of $5 \mathrm{~km}, 4 \mathrm{GHz} \mathrm{RF}$ range and PEs with 0, 2.5, 5 and 8 deg.

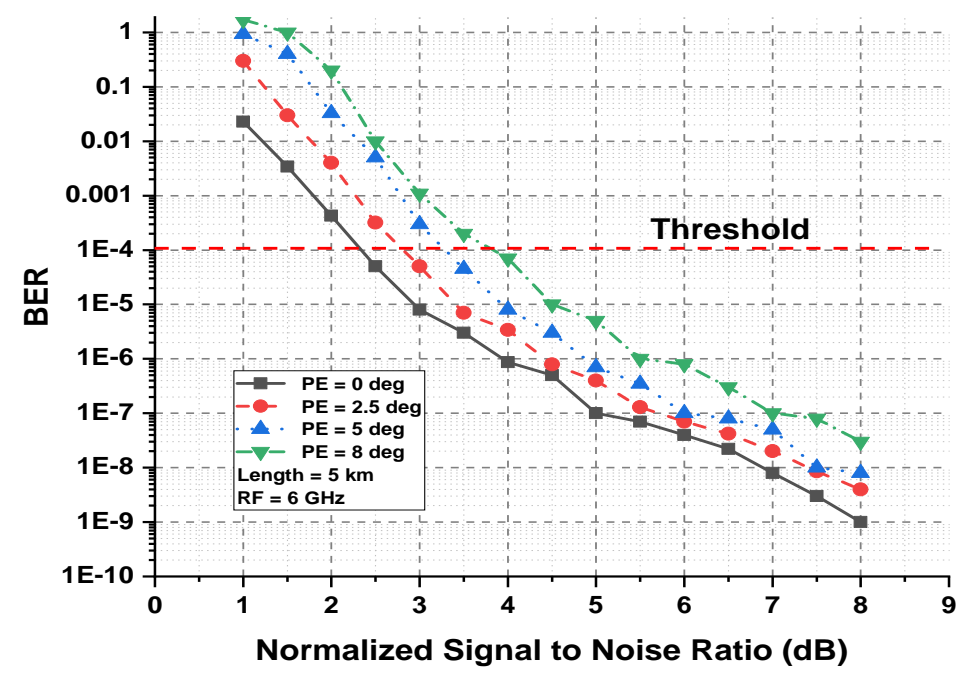

Figure 5. Normalized signal to noise ratio vs BER at 0, 2.5, 5 and 8 deg of PEs, $6 \mathrm{GHz}$ RF range, fiber length with magnitude of $10 \mathrm{~km}$ and $100 \mathrm{Gbps}$ data rate. 


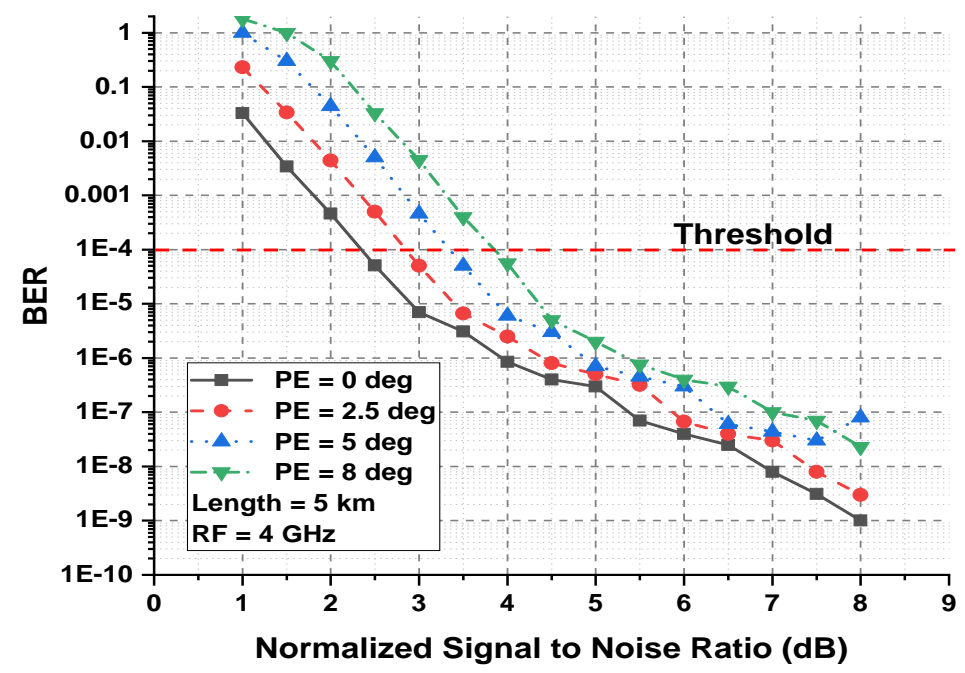

Figure 6. Results among BER and normalized signal to noise ratio with length $=10 \mathrm{~km}, \mathrm{RF}=4 \mathrm{GHz}$, data rate $=100 \mathrm{Gbps}$ and PEs $=0,2.5,5$ and $8 \mathrm{deg}$.

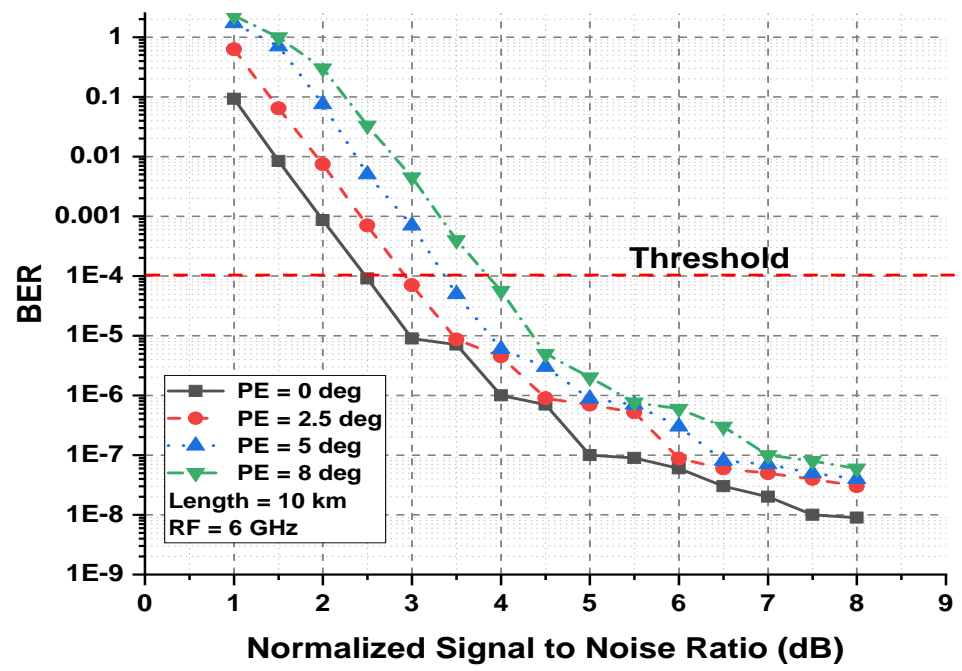

Figure 7. Simulation analysis for $10 \mathrm{~km}$ of optical fiber, $100 \mathrm{Gbps}$ data rate, PEs with $0,2.5,5$ and 8 deg and $6 \mathrm{GHz}$ RF magnitude based on normalized signal to noise ratio and BER.

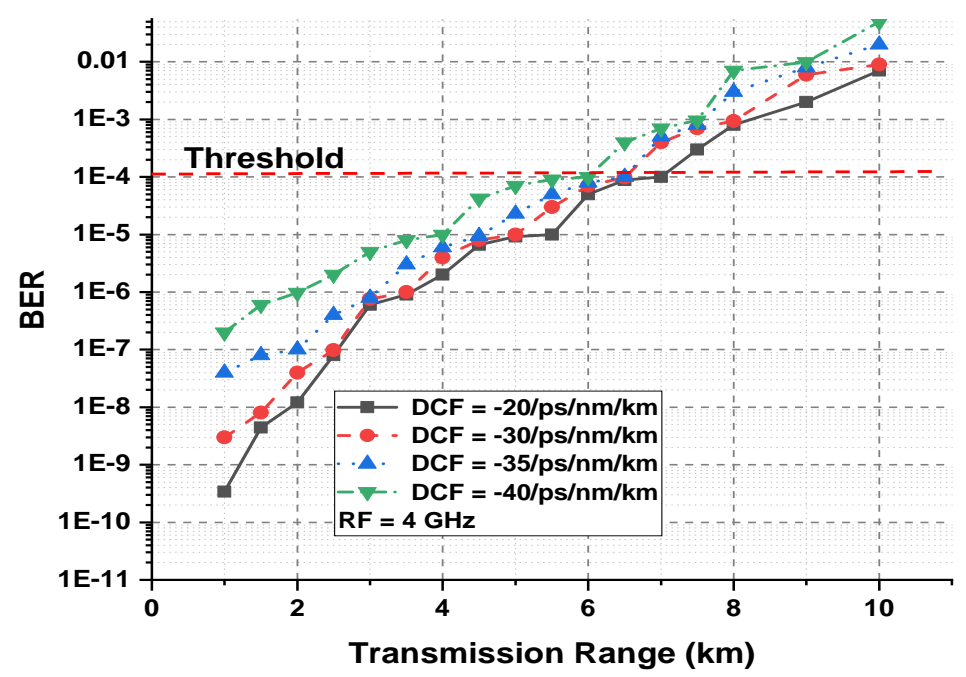

Figure 8. Estimation of $-20,-30,-35$ and $-40 \mathrm{ps} / \mathrm{nm} / \mathrm{km}$ DCF with transmission range as a function of BER at $\mathrm{RF}=4 \mathrm{GHz}$, data rate $=100 \mathrm{Gbps}$ and 16 channels (Updated). 


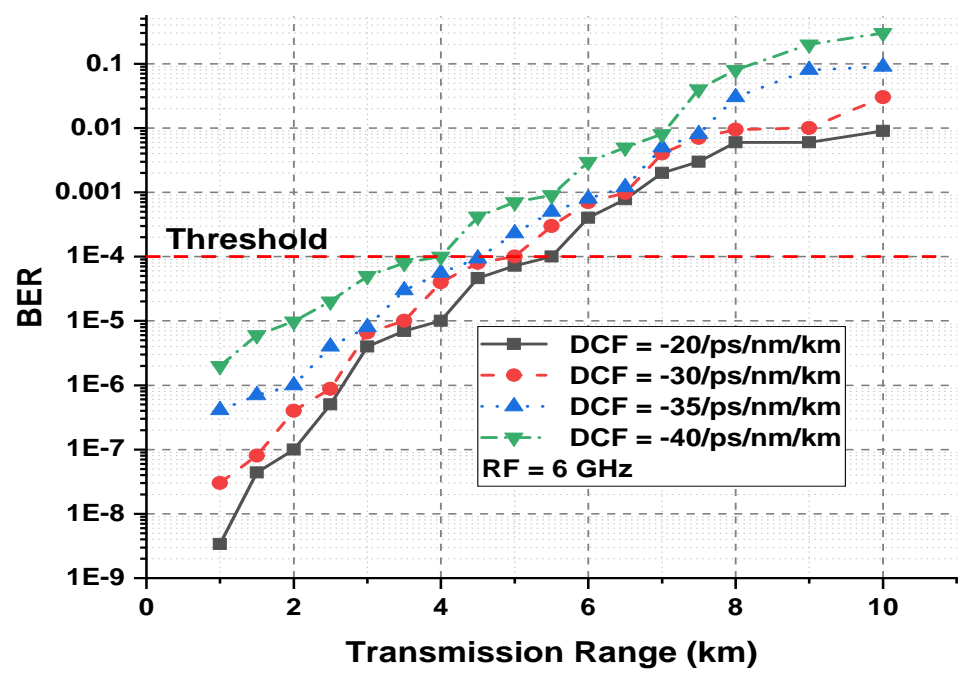

Figure 9. BER against transmission path cover at $6 \mathrm{GHz}$ of $\mathrm{RF}$ waves, DCF $=-20,-30,-35$ and 40 here. $\mathrm{ps} / \mathrm{nm} / \mathrm{km}$, data rate $=100 \mathrm{Gbps}$ and channels $=16$.

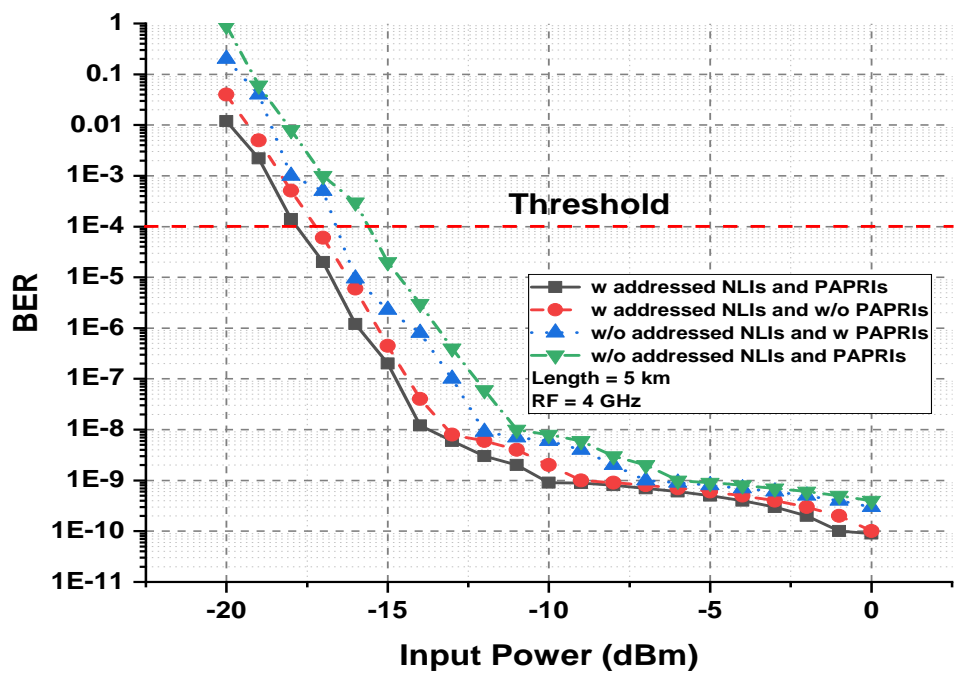

Figure 10. Input power in terms of BER at length $5 \mathrm{~km}$ and $4 \mathrm{GHz}$ RF range for evaluating with and without addressed NLIs and PAPRIs.

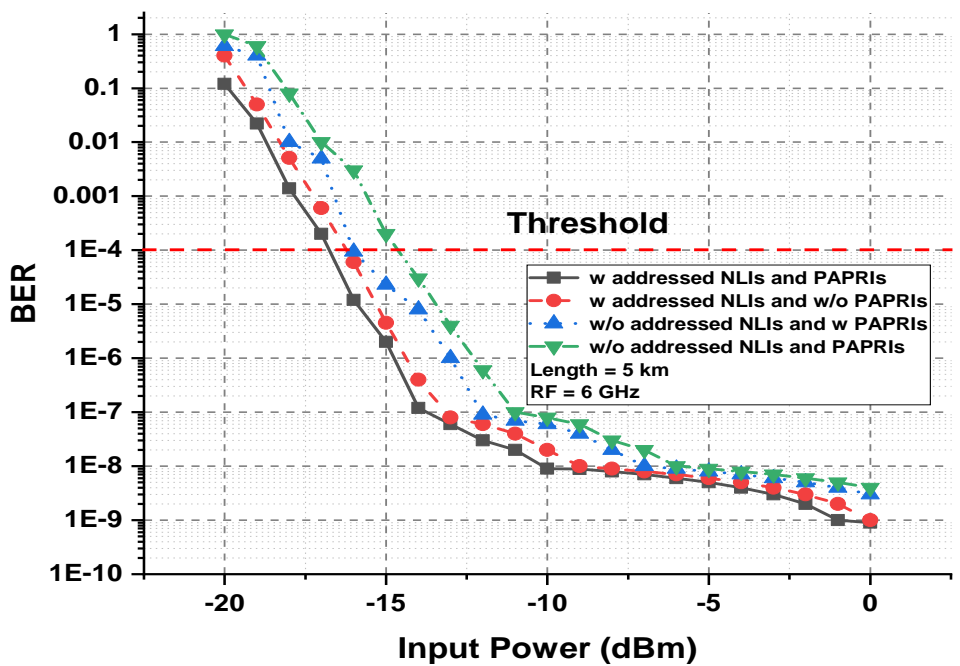

Figure 11. BER as a function of launch power with $5 \mathrm{~km}$ fiber length and $6 \mathrm{GHz}$ frequency range. 


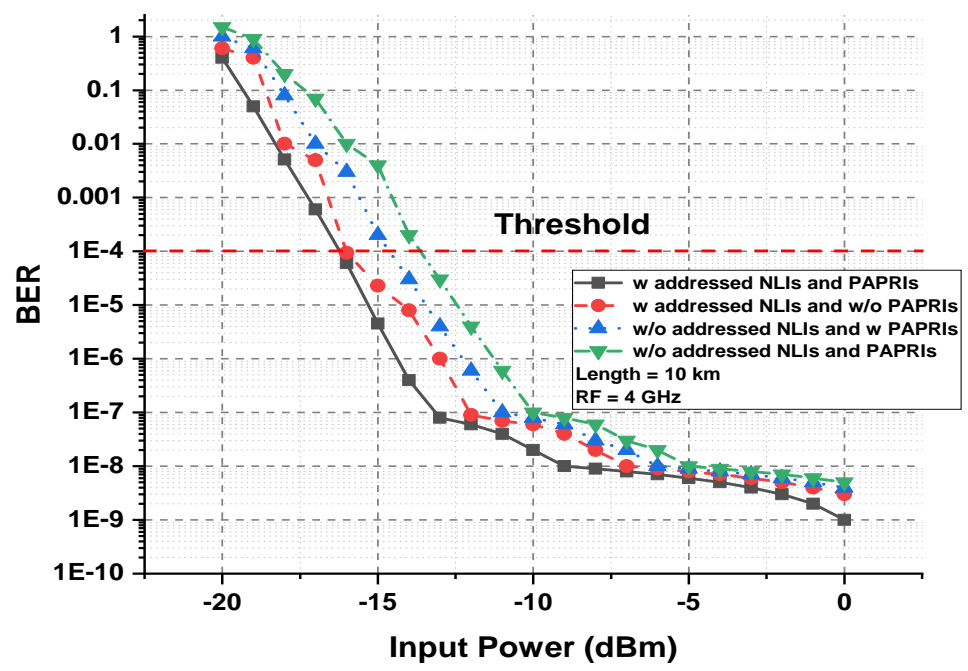

Figure 12. Launch power against BER for length of $10 \mathrm{~km}, \mathrm{RF}=4 \mathrm{GHz}$ at with and without addressed NLIs and PAPRIs.

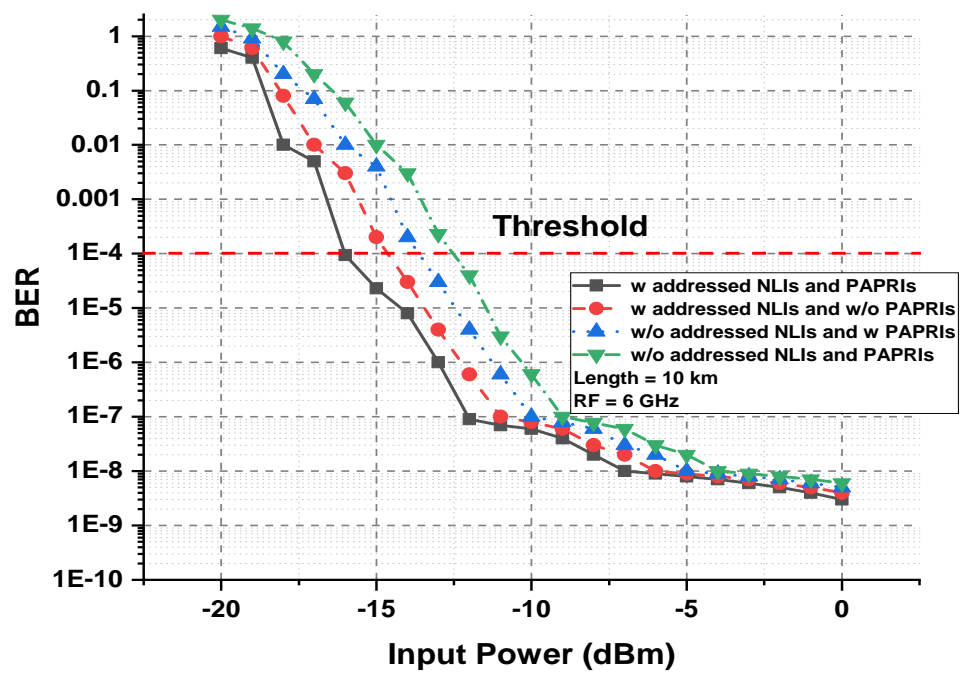

Figure 13. Input power against BER for $6 \mathrm{GHz}$ RF values, length $=10 \mathrm{~km}$, data rate $=100 \mathrm{Gbps}$ and channels $=16$ to analyze NLIs and PAPRIs.

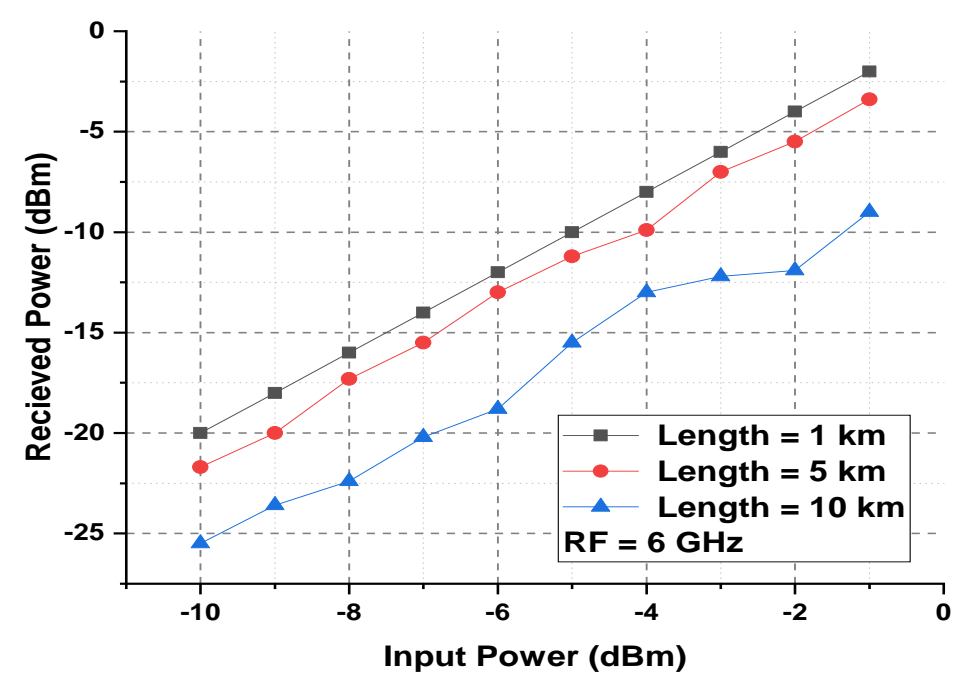

Figure 14. Output power vs input power for 1,5 and $10 \mathrm{Km}$ and $\mathrm{RF}=6 \mathrm{GHz}$. 


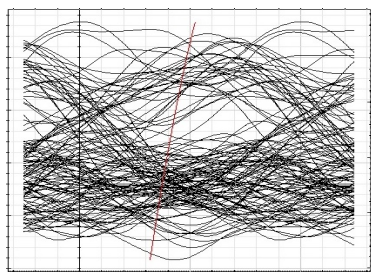

(a)

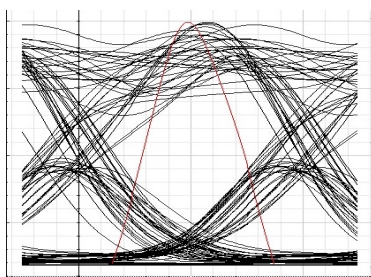

(d)

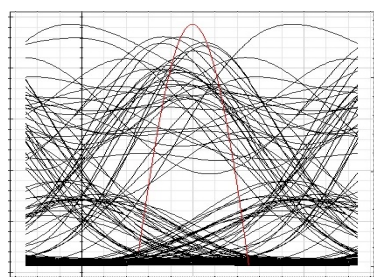

(b)

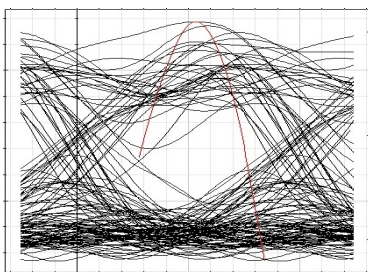

(c)

Figure 15. BER eye-diagrams; (a) BER at $10 \mathrm{~km}$ distance and $6 \mathrm{GHz}$ RF without addressed NLIs, and PAPRIs, (b) BER at length $=10 \mathrm{~km} \mathrm{RF}=4 \mathrm{GHz}$ without addressed NLIs and PAPRIs, (c) BER at $10 \mathrm{~km}$ distance and $6 \mathrm{GHz}$ RF with addressed NLIs and PAPRIs, and (d) BER at L = $10 \mathrm{~km}$ distance and $\mathrm{RF}=4 \mathrm{GHz}$ with addressed NLIs and PAPRIs.

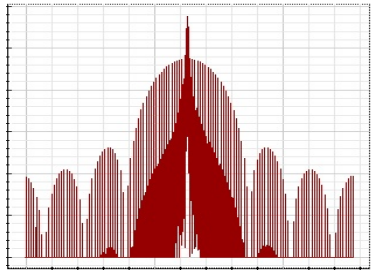

(a)

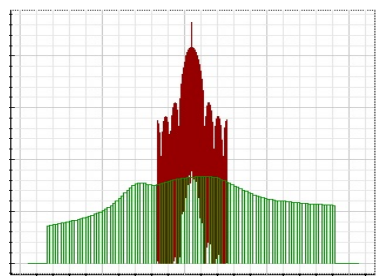

(d)

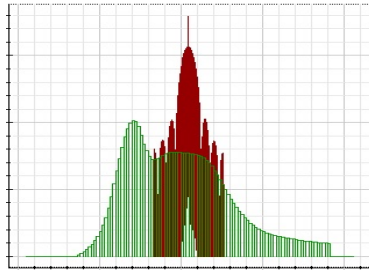

(b)

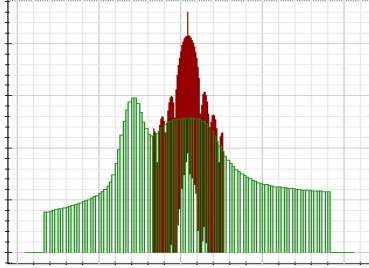

(c)

Figure 16. Optical spectrum analyzer; (a): Input transmitted signals, (b): Without addressed of NLIs and PAPRIs at $5 \mathrm{~km}$ of length, (c): Without addressed of NLIs and PAPRIs at $10 \mathrm{~km}$ of length, (d): Output signals with managed of NLIs and PAPRIS at $10 \mathrm{~km}$ of length.

The proposed outcomes, which are explained in Figures 3-17d depict that the performance of the treated NLIs and PAPRIs model is efficient many times as compared to without approached NLIs and PAPRIs. The presented RoF model outcomes are correlated with existed models as shown in Table 2, which specifies the fruitful outcomes of the proposed framework. 


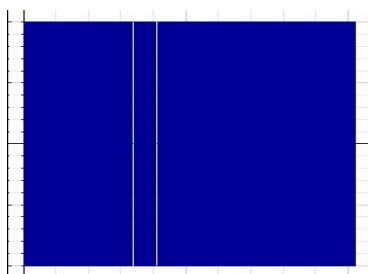

(a)

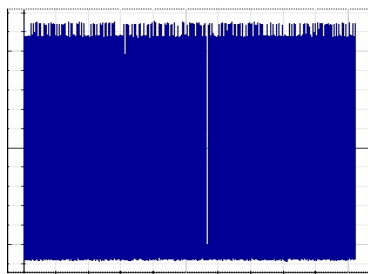

(d)

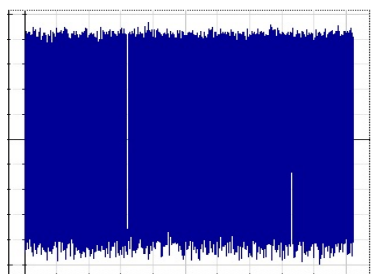

(b)

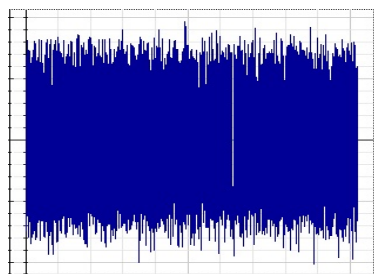

(c)

Figure 17. RF spectrum analyzer; (a): Input signals, (b): NLIs and PAPRIs interrupted signals, (c): Interrupted signals due to NLIs, and PAPRIs at length $=5 \mathrm{~km}$ and RF $=4 \mathrm{GHz}$, (d): Output signals with addressed NLIs, and PAPRIs with length $=5 \mathrm{~km}$ and $\mathrm{RF}=4 \mathrm{GHz}$.

Table 2. Correlation of proposed framework with existed models.

\begin{tabular}{lccc}
\hline Parameter Description & [37] & [38] & Presented RoF Model \\
\hline Modulation scheme & OFDM & 64-QAM & Dual drive and dual port liNb MZM \\
Received power $(\mathrm{dBm})$ & -35 to $-25 \mathrm{dBm}$ & -40 to $-22 \mathrm{dBm}$ & -36 to $-18 \mathrm{dBm}$ \\
Input Power $(\mathrm{dBm})$ & -22 to $-3 \mathrm{dBm}$ & -23 to $-2 \mathrm{dBm}$ & -20 to $-0 \mathrm{dBm}$ \\
Input Power $(\mathrm{dBm})$ & -22 to $-3 \mathrm{dBm}$ & -23 to $-2 \mathrm{dBm}$ & -20 to $-0 \mathrm{dBm}$ \\
Length & $6 \mathrm{~km}$ & $8 \mathrm{~km}$ & $10 \mathrm{~km}$ \\
BER & $1.4 \times 10^{-3}$ & $2 \times 10^{-5}$ & $4.1 \times 10^{-7}$ \\
\hline
\end{tabular}

\section{Conclusions}

The full duplex RoF model is considered a fruitful solution in current era to support maximum number of users including video based services. Therefore, in this paper a full duplex WDM based RoF model is projected in terms of hybrid coupling mechanism. The prominent factors like NLIs and PAPRIs are studied and minimized in this presented model. The background of the proposed model is analyzed with RF and optical domain infrastructure. Mathematical model is investigated to explore the originality of transmitted signals, the discontinuity of pulses due to optical domain and electrical domain related issues like NLIs, and PAPRIs, using the proposed analytical model. The presented results are investigated in terms of $1 \mathrm{~km}$ to $10 \mathrm{~km}$ of transmission range 4 and $6 \mathrm{GHz}$ of RF magnitudes, input power between -20 to $0 \mathrm{dBm}$, received power with -40 to $-18 \mathrm{dBm}$ values and 0 to 8 normalized to signal noise ratio. It is concluded that there is a clear difference among with suppressed NLIs, and PAPRIs and without managed NLIs and PAPRIs.

Author Contributions: Data curation-H.Y.; Formal analysis-S.T., A.A., F.M. and F.A. (Fayadh Alenezi); Funding acquisition-H.Y., S.T. and N.A.; Investigation-F.A. (Farman Ali), S.T., A.A., F.M., F.A. (Fayadh Alenezi) and K.H.; Methodology-A.A. and F.M.; Project administration-F.A. (Farman Ali); Resources-F.A. (Fayadh Alenezi) and K.H.; Software-F.A. (Fayadh Alenezi) and K.H.; Supervision-A.A.; Visualization-F.M., F.A. (Fayadh Alenezi) and N.A.; Writing—original draft, H.Y. and F.A. (Farman Ali); Writing-review \& editing, S.T., H.K., A.A. and F.M. All authors have read and agreed to the published version of the manuscript.

Funding: This work is supported in part by the Beijing Natural Science Foundation (No. 4212015), Natural Science Foundation of China (No. 61801008), China Ministry of Education-China Mobile Scientific Research Foundation (No. MCM20200102), China Postdoctoral Science Foundation (No. 
2020M670074), Beijing Municipal Commission of Education Foundation (No. KM201910005025), China National Key Research and Development Program (No. 2018YFB0803600).

Institutional Review Board Statement: Not applicable.

Informed Consent Statement: Not applicable.

Data Availability Statement: Data will be available as per request.

Acknowledgments: This work is supported in part by the Beijing Natural Science Foundation (No. 4212015), Natural Science Foundation of China (No. 61801008), China Ministry of Education-China Mobile Scientific Research Foundation (No. MCM20200102), China Postdoctoral Science Foundation (No. 2020M670074), Beijing Municipal Commission of Education Foundation (No. KM201910005025), China National Key Research and Development Program (No. 2018YFB0803600).

Princess Nourah bint Abdulrahman University Researchers Supporting Project number (PNURSP2022R192), Princess Nourah bint Abdulrahman University, Riyadh, Saudi Arabia.

Conflicts of Interest: The authors declare no conflict of interest.

\section{References}

1. Khan, Y.; Ali, F.; Ali, A. Impact of nonlinear impairments on power budget and transmission power penalties in high capacity long haul optical networks. Wirel. Pers. Commun. 2019, 106, 1001-1013. [CrossRef]

2. Sharma, S.R.; Rana, S. Comprehensive Study of Radio over Fiber with different modulation techniques-A review. Int. J. Comput. Appl. 2017, 170, 22-25. [CrossRef]

3. Anjum, O.F.; Horak, P.; Jung, Y.; Suzuki, M.; Yamamoto, Y.; Hasegawa, T.; Petropoulos, P.; Richardson, D.J.; Parmigianil, F. Bandwidth enhancement of inter-modal four wave mixing Bragg scattering by means of dispersion engineering. APL Photonics 2018, 4, 368-370. [CrossRef]

4. Irfan, M.; Ali, F.; Muhammad, F.; Habib, U.; Alwadie, A.S.; Glowacz, A.; Abbas, Z.H. DSP-Assisted nonlinear impairments tolerant $100 \mathrm{Gbps}$ optical backhaul network for long-haul transmission. Entropy 2020, 22, 1062. [CrossRef]

5. El-Nahal, F.I.A. WDM-PON with DPSK modulated downstream and OOK modulated upstream signals based on symmetric $10 \mathrm{Gbit} / \mathrm{s}$ wavelength reused bidirectional reflective SOA. Optoelectron. Lett. 2017, 13, 67-69. [CrossRef]

6. Ali, F.; Khan, Y.; Qureshi, S.S. Transmission performance comparison of $16^{*} 100 \mathrm{Gbps}$ dense wavelength division multiplexed long haul optical networks at different advance modulation formats under the influence of nonlinear impairments. J. Opt. Commun. 2018. [CrossRef]

7. Cartledge, J.C.; Guiomar, F.P.; Kschischang, F.R.; Liga, G.; Yankov, M.P. Digital signal processing for fiber nonlinearities. Opt. Express 2017, 25, 1916-1936. [CrossRef] [PubMed]

8. $\quad$ Bakhshali, A.; Chan, W.Y.; Cartledge, J.C.; OSullivan, M.; Laperle, C.; Borowiec, A.; Roberts, K. Frequency-domain Volterra-based equalization structures for efficient mitigation of intrachannel Kerr nonlinearities. J. Light. Technol. 2016, 34, 1770-1777. [CrossRef]

9. Liu, X.; Chraplyvy, A.; Winzer, P.; Tkach, R.; Chandrasekhar, S. Phase-conjugated twin waves for communication beyond the Kerr nonlinearity limit. Nat. Photonics 2013, 7, 560. [CrossRef]

10. Ali, F.; Muhammad, F.; Habib, U.; Khan, Y.; Usman, M. Modeling and minimization of FWM effects in DWDM-based long-haul optical communication systems. Photon Netw. Commun. 2021, 41, 36-46. [CrossRef]

11. Habib, U.; Aighobahi, A.E.; Wang, C.; Gomes, N.J. Radio over fiber transport of mm-Wave $2 \times 2$ MIMO for spatial diversity and multiplexing. In Proceedings of the IEEE International Topical Meeting on Microwave Photonics (MWP), Long Beach, CA, USA, 31 October-3 November 2016; pp. 39-42.

12. Wang, B.; Peng, L.; Ho, P. Energy-efficient radio-over-fiber system for next-generation cloud radio access networks. J. Wirel. Com. Netw. 2019, 2019, 118. [CrossRef]

13. Ali, A.H.; Farhood, A.D. Design and performance analysis of the WDM Schemes for radio over fiber system With different fiber propagation losses. Fibers 2019, 7, 19. [CrossRef]

14. Li, G.; Lin, Z.; Huang, X.; Li, J. A radio over fiber system with simultaneous wireless multi-mode operation based on a multi-wavelength optical comb and pulse-shaped 4QAM-OFDM. Electronics 2019, 8, 1064. [CrossRef]

15. Li, J.L.; Zhao, F.; Yu, J. D-band millimeter wave generation and transmission though radio-over-fiber system. IEEE Photonics J. 2019, 12, 5500708. [CrossRef]

16. Li, W.; Chen, A.; Li, T.; Penty, R.V.; White, I.H.; Wang, X. Novel digital radio over fiber (DRoF) system with data compression for neutral-host fronthaul applications. IEEE Access 2020, 8, 40680-40691. [CrossRef]

17. Sharma, V.; Sergeyev, S.; Kaur, J. Adaptive $2 \times 2$ MIMO employed wavelet-OFDM-radio over fibre tTransmission. IEEE Access 2020, 8, 23336-23345. [CrossRef]

18. Kim, J.; Lee, H.; Park, S.; Lee, I. Minimum rate maximization for wireless powered cloud radio access networks. IEEE Trans. Veh. Technol. 2019, 68, 1045-1049. [CrossRef]

19. Muramoto, K.; Inoue, A.; Koike, Y. Noise and distortion reduction in OFDM radio-over-fiber link by graded-index plastic optical fiber. IEEE Photonics Technol. Lett. 2020, 32, 835-838. [CrossRef] 
20. Qamar, F.; Islam, M.K.; Ali, S.Z.; Ali, M. Secure duobinary signal transmission in optical communication networks for high performance \& reliability. IEEE Access 2018, 5, 17795-17802.

21. Zhang, H.; Batshon, H.G.; Davidson, C.R.; Foursa, D.G.; Pilipetskii, A. Multi dimensional coded modulation in long-haul fiber optic transmission. J. Light. Technol. 2015, 33, 2876-2883. [CrossRef]

22. Stojanovic, N.; Changsong, X. An efficient method for skew estimation and compensation in coherent receivers. IEEE Photonics Technol. Lett. 2016, 28, 489-492. [CrossRef]

23. Tanimura, T.; Hoshida, T.; Kato, T.; Watanabe, S. OSNR estimation providing self-confidence level as auxiliary output from neural networks. J. Lightw. Technol. 2019, 37, 1717-1723. [CrossRef]

24. Zhuge, Q.; Chen, X. Advances in modulation and DSP for optical transmission systems. J. Opt. Commun. 2018, 409, 1-136. [CrossRef]

25. Ali, F.; Ahmad, S.; Muhammad, F.; Abbas, Z.H.; Habib, U.; Kim, S. Adaptive equalization for dispersion mitigation in multichannel optical communication networks. Electronics 2019, 8, 1364. [CrossRef]

26. Maharana, D.; Rout, R. A 4 channel WDM based hybrid optical Fiber/FSO communication system using DP QPSK modulation for bit rate of 100/112 Gb/s. Int. J. Eng. Res. Technol. 2019, 8, 442-445.

27. Obaid, H.M.; Shahid, H. Achieving high gain using Er-Yb codoped waveguide/fiber optical parametric hybrid amplifier for dense wavelength division multiplexed system. Opt. Eng. 2018, 57, 056108. [CrossRef]

28. Argyris, N.; Giannoulis, G.; Kanta, K.; Iliadis, N.; Vagionas, C.; Papaioannou, S.; Kalfas, G.; Apostolopoulos, D.; Caillaud, C.; Debrégeas, H.; et al. A $5 \mathrm{G}$ mmWave fiber-wireless IFoF analog mobile fronthaul link with up to $24 \mathrm{~Gb} / \mathrm{s}$ multi-band wireless capacity. J. Lightw. Technol. 2019, 37, 2883-2891. [CrossRef]

29. Ali, F.; Khan, Y.; Muhammad, F.; Habib, U.; Abbas, Z.H.; Khan, M.A.; Ali, A. Extenuation of phase shift influenced nonlinear impairments in fiber optics network. Trans. Emerg. Telecommun. Technol. 2020, 31, e3930. [CrossRef]

30. Tipsuwannakul, E.; Li, J.; Karlsson, M.; Andrekson, P.A. Performance comparisons of DP16-QAM and duobinary-shaped DP-QPSK for optical systems with $4.1 \mathrm{Bit} / \mathrm{s} / \mathrm{Hz}$ spectral efficiency. J. Light. Technol. 2012, 30, 2307-2314. [CrossRef]

31. Noor, S.; Assimakopoulos, P.; Gomes, N.J. A flexible subcarrier multiplexing system with analog transport and digital processing for 5G (and beyond) fronthaul. J. Lightw. Technol. 2019, 37, 3689-3700. [CrossRef]

32. Yu, W.; Zeng, B.; Peng Yan, S.; Huang, Y.; Jiang, H. Multi-objective optimum design of high-speed backplane connector using particle swarm optimization. IEEE Access 2018, 6, 35182-35193. [CrossRef]

33. Perin, J.K.; Shastri, A.; Kahn, J. Design of low-power DSP-free coherent receivers for data center links. J. Light. Technol. 2017, 35, 4650-4662. [CrossRef]

34. Miao, X.; Bi, M.; Fu, Y.; Li, L.; Hu, W. Experimental study of NRZ, Duobinary, and PAM-4 in O-band DML-based 100G-EPON. IEEE Photonics Technol. Lett. 2017, 29, 1490-1493. [CrossRef]

35. Dong, Y.; Al-Rawachy, E.; Giddings, R.P.; Jin, W.; Nesset, D.; Tang, J.M. Multiple channel interference cancellation of digital filter multiple access PONs. J. Light. Technol. 2017, 35, 34-44. [CrossRef]

36. Muhammad, F.; Ali, F.; Habib, U.; Usman, M.; Khan, I.; Kim, S. Time domain equalization and digital back-propagation method-based receiver for fiber optic communication systems. Int. J. Opt. 2020, 2020, 3146374. [CrossRef]

37. Dat, P.T.; Kanno, A.; Inagaki, K.; Kawanishi, T. High-Capacity Wireless Backhaul Network Using Seamless Convergence of Radio-over-Fiber and 90-GHz Millimeter-Wave. J. Light. Technol. 2014, 32, 3910-3923. [CrossRef]

38. Vázquez, C.; López-Cardona, J.D.; Lallana, P.C.; Montero, D.S.; Al-Zubaidi, F.M.A.; Pérez-Prieto, S.; Garcilópez, I.P. Multicore Fiber Scenarios Supporting Power Over Fiber in Radio Over Fiber Systems. IEEE Access 2019, 7, 158409-158418. [CrossRef] 